\title{
Identifying the Potential Role of Women in Pharmacy by Proposing a Model using Data Mining
}

\author{
Radha D. \\ M.O.P Vaishnav College for \\ Women, Chennai
}

\author{
Ankitha A. \\ M.O.P Vaishnav College for \\ Women, Chennai
}

\author{
Revathi A. \\ M.O.P Vaishnav College for \\ Women, Chennai
}

\begin{abstract}
Pharmacy is a practice of preparing and dispensing of medicinal drugs. Data mining is a process of discovering patterns in large data sets involving techniques at intersection of data science, artificial intelligence, machine learning, statistics, and DBMS. It holds the great potential for the healthcare industry to systematically use health data and analytics to identify inefficiencies. The paper aims to analyze the key factors which lead to increase the sale rate in a pharmacy by predicting that women assistant in a pharmacy is also a key factor to increase the sale.
\end{abstract}

\section{General Terms}

The key factors are predicted by using Covariance Matrix. Covariance measures the strength of the correlation between two or more sets of random variables.

\section{Keywords}

Data Mining, Pharmacy, Sales, Statistics, Mining Software, Covariance Matrix, Women Assistants.

\section{INTRODUCTION}

Data mining is the analysis process of the 'Knowledge Discovery in Database' process or KDD. It's defined as the nontrivial extraction of implicit unknown and potentially useful information from the data. It allows users to analyze data from different dimension, categorize and summarize the relationship identified. Since, the health care process being a data rich platform, many potential patterns can be discovered by the data mining techniques. The objective of this paper is to find whether a women assistant in a pharmacy play a key factor in increase of sales rate. The five factors considered are 24 Hrs Service, Door Delivery, Women Assistant, Specific Location and Anchored by Hospital. The concept used in proving the proposed model is the Covariance Matrix. Covariance Matrix is similar to the matrices used in statistics and is symmetric.

\section{LITERATURE REVIEW}

Data mining applications involved in the healthcare are useful to analyze hidden patterns and derive useful information. According to

\subsection{Knifedge Word Press}

Most of the medical stores are run by men and very rare to see a woman run a medical store which is a normal thing in India. Usually whenever we do have some problems we ask the store owner to suggest some medicine and accordingly and take those. Even if men having troubles in covered areas, they hardly hesitate to ask the medicine shop owner. But think for a while, if women have some problems in their covered areas, they hardly approach to the men store owners and ask for medicines. In that case either they ask to the family or they do the medication on their own. By suggesting local medicine shop owner to have a lady may be his mother, sister, or near relative who is comfortable with medications and overall ideas .The word press quoted that "Am sure lot of women will approach to the lady and it's quite comfortable to express and thus sales will rise".

\subsection{Don Dietz, R.Ph, MS, Vice President, Pharmacy Healthcare Solutions, Inc.}

According to the presentation, the existing technology and automation strategies used by pharmacies to maintain pharmacy profitability and identify future solutions for pharmacy to sustain long term profitability via technology, staffing and new revenue streams are described.

\subsection{Harish Sujan, Barton A Weitz, and Mita Sujan}

The research with over 2000 sales-people working for over 200 companies indicates that a key factor for increasing sales force productivity is getting sales people to work smarter during their interactions with customers and they found that the better salespeople work smarter, they practice adaptive selling, i.e., they alter their sales approaches based on the nature of the customer to whom they are selling. While the notion that effective selling requires the salesperson to be sensitive to the needs of the customer and to the demands the selling environment and what is missing is a more precise understanding of what constitutes working smarter during a customer-salesperson interaction.

\subsection{McKesson}

This research is about the Strategies to Boost Sales of Pharmacy. The key factors considered are Building Customer Relationships, Designing floor plan to generate sales, Check out market research, Draw customers more frequently, Sell with stellar service and Elaborate about the smartness of the pharmacy during the customer-salesperson interaction.

\subsection{Hamuro, Naokikatoh, Yasuyuki \\ Matsuda, Katsutoshi Yada}

The researchers state that Pharma is a voluntary drugstore chain consisting of 1,230 retail shops across the country. Total annual sales reach approximately seventy billion yen and its membership club has more than 2.3 million customers. The main tasks of Pharma headquarters are to collect order data from retailers and send it on to wholesalers who deliver to the ordering retailer, to maintain customer and sales information, and to provide research reports on consumer behavior to manufacturers. Over a decade Pharma has accumulated an average of $60 \mathrm{~GB}$ of sales data annually. Pharma provides

in valuable information about consumer behavior to manufactures, achieving favorable position in trade and competitive advantage. 


\section{SYSTEM MODEL}

The dataset information was gathered from various women such as college girls and office workers and those data were analyzed. The data was mostly collected from women to find out does really a women assistant can play a key factor in increasing sales rate in a pharmacy. The survey was conducted and the results were stored in the database. In this technique, the proposed model is built using large amount of data. Using this model, the data collected is analyzed and new strategies were evolved to improve the sales and profits. To build the proposed model, the data mining tool Rapid miner was used. The tool provides an integrated environment for machine learning, data mining, text mining, predictive analytics and business analytics. This tool is used for business and industrial applications as well as for research, education, training, rapid prototyping, and application development and supports all steps of the data mining process including results visualization, validation and optimization. The data mining tool uses a client/server model with the server offered as Software as a Service or on cloud infrastructures. The result of the analysis proved that women assistant in a pharmacy is also one among the key factor in increasing the sales rate like the other factors such as 24 Hrs Service, Door Delivery, Specific Location and Anchored by Hospital.

\section{PERFORMANCE AND ANALYSIS}

The dataset collected for predicting the various key factors to increase the sales in a pharmacy are 24 Hrs Service, Door Delivery, Anchored by Hospital, Women Attendants, Locations.

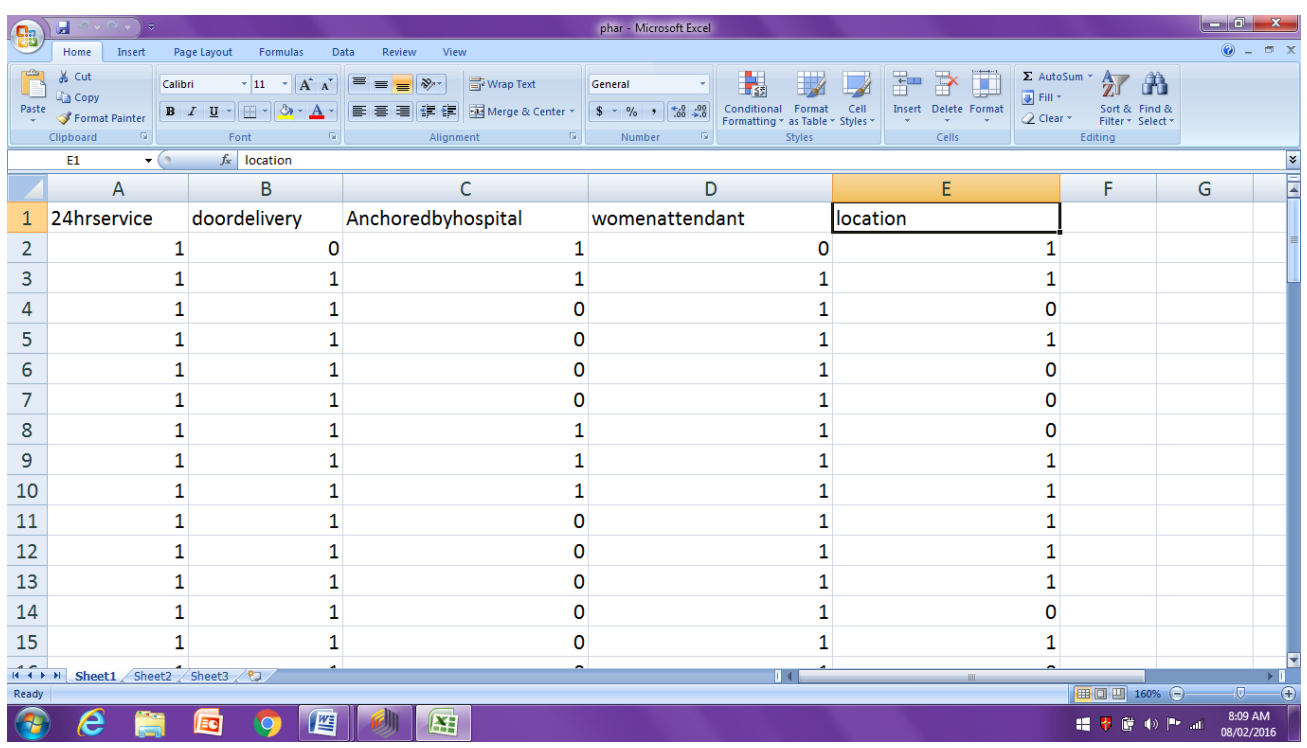

Figure 1

The survey was conducted and the results were stored in the database (as shown in Figure 1) and values were given such as 1 if the user accepts, 0 if the user denies for the attributes specified in the table. The data from the worksheet was imported into the data mining software and was analyzed, before forming the covariance matrix .The data was stored in the tool then was analyzed by covariance matrix operator (as shown in Figure 2).

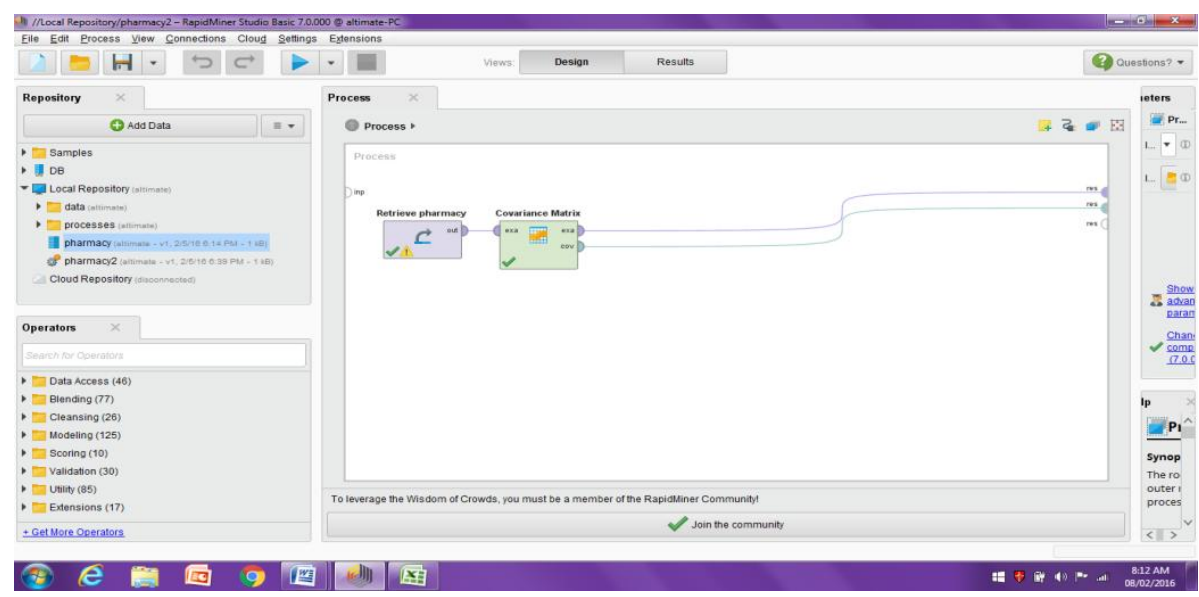

Figure 2

The data served as input to the covariance matrix operator which is a built in operator in the rapid miner tool and Covariance Matrix means that the table has the same headings across the top as it does along the side. The covariance matrix operator formed the covariance table once the input was imported to the operator (as shown in Figure 3). 


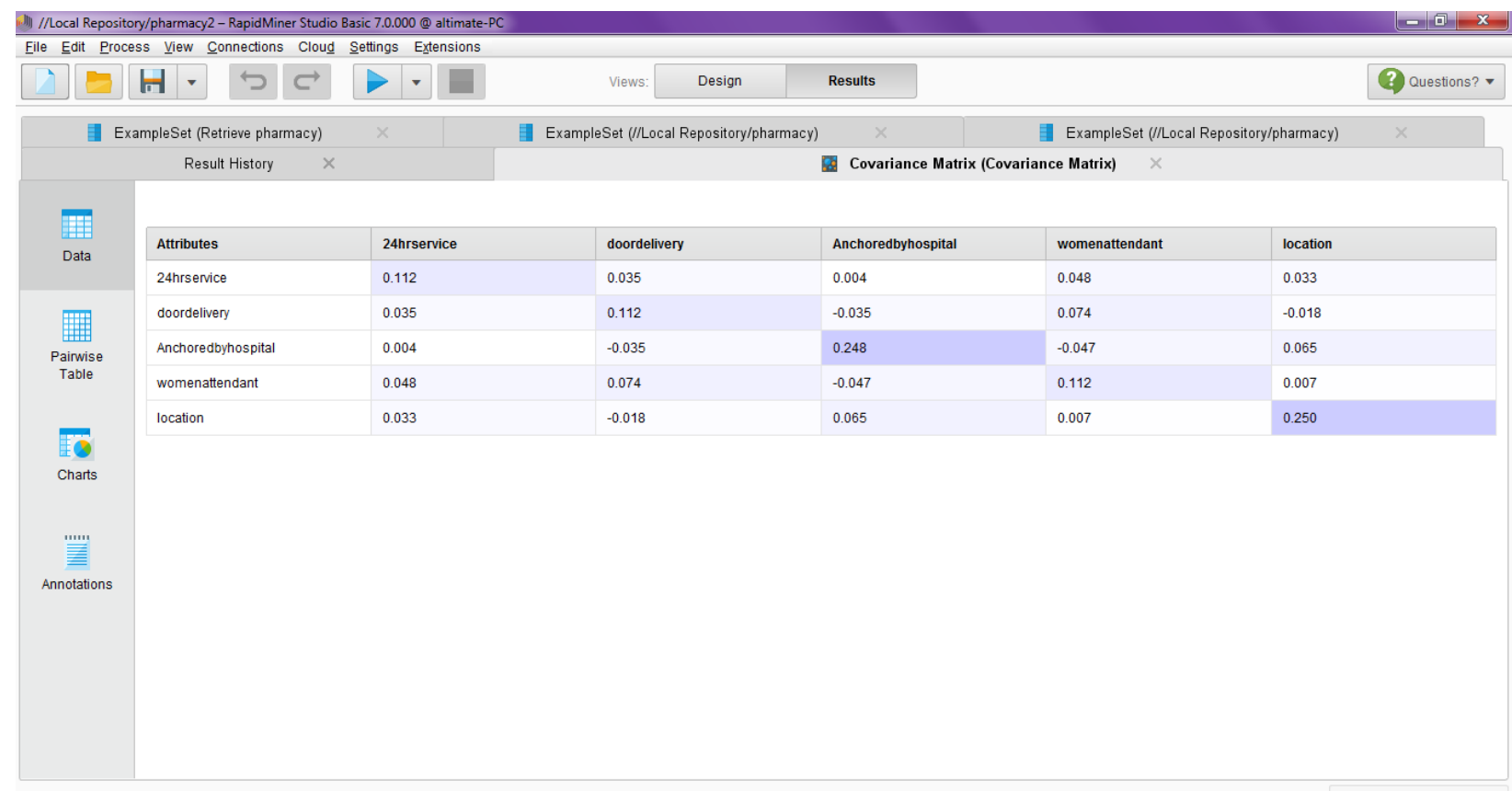

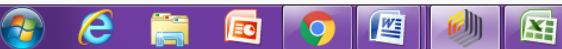

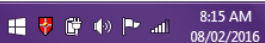

Figure 3

After the covariance table was formed, the pair wise table was calculated by the mining tool and the table stated that if the attributes is high i.e. factors that will lead to increase sales and if negative then factors doesn't much contribute in increased results tends to be positive then interrelationship among sale (as shown in Figure 4).

\begin{tabular}{|l|l|l|l|l|l|}
\hline & & \\
\hline
\end{tabular}

\section{Figure 4}

The pair wise table was utilized to form the bar chart (as shown in Figure 5). It is a chart that presents grouped data with rectangular bars with lengths proportional to the values that they represent. The chart formed by the covariance matrix proved that women assistant also play a key factor in increasing the sales in a pharmacy like other factors such as door delivery, location, anchored by hospital. 


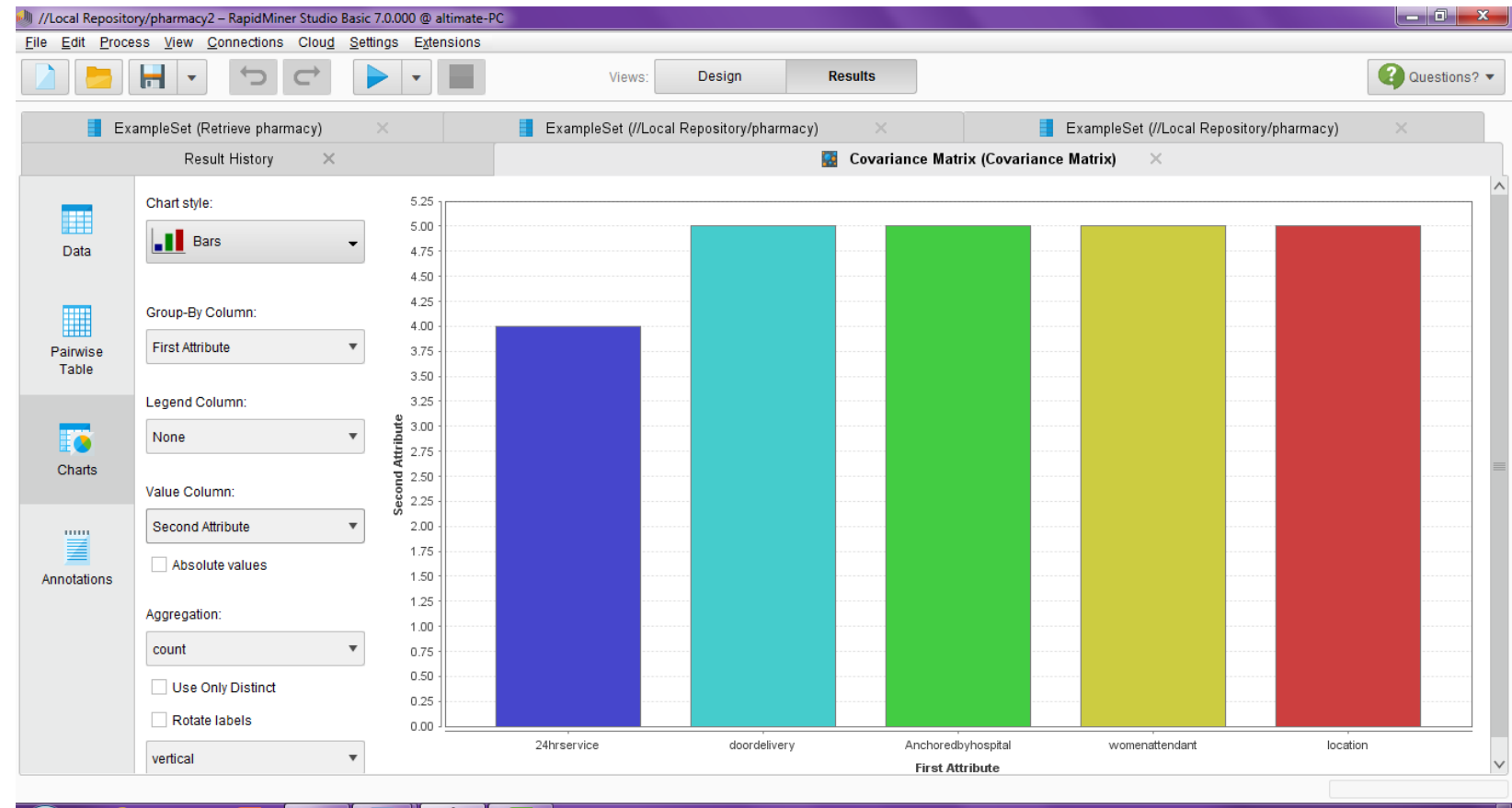

Figure 5

The above chart produced by the covariance matrix model proves that women assistant do play a major role as a key factor in increasing the sales in a pharmacy.

\section{CONCLUSION}

Data mining holds great potential to enable health systems to systematically use data and analytics to identify inefficiencies and best practices that improve care and reduce costs in healthcare industry. Healthcare has been slow to incorporate the latest research into everyday practice. The main objective of the paper that women assistant in a pharmacy is also a key factor to increase the sale rate is accomplished. The paper concludes that a pharmacy with women assistant will increase the sale rate in addition to other strategies through the rapid mining tool. The future enhancements of the paper could be how to expand the business to high platforms by analyzing the key factors to boost their business cycle.

\section{REFERENCES}

[1] https://www.google.co.in/webhp?sourceid=chromeinstant\&ion $=1 \&$ espv $=2 \&$ ie $=$ UTF\#q=how\%20to\%20increase\%20pharmacy\%20sales

[2] http://www.tandemwest.ru/en/f_a_q/ideas_and_experien ce/merchandising/how_to_increase_retail_pharmacy_sal es_by_means_of_merchandising/

[3] http://ieeexplore.ieee.org/xpl/login.jsp?tp=\&arnumber=5 995169\&url=http\%3A\%2F\%2Fieeexplore.iee. org\%2Fie $15 \% 2 \mathrm{~F} 4233 \% 2 \mathrm{~F} 6083501 \% 2 \mathrm{~F} 05995169$.pdf\%3Farnumbe r\%3D5995169
[4] http://smartretailingrx.com/revenue-opportunities/9ways-help-increase-front-end-sales/

[5] https://www.google.co.in/search?q=pharmacy\&oq=phar macy\&aqs=chrome..69i57j69i6013j69i61.3156j0j7\&sour ceid $=$ chrome\&es_sm $=93 \&$ ie $=$ UTF-

$8 \# q=$ what + is + pharmacy

[6] http://mathworld.wolfram.com/Covariance.html

[7] https://www.healthcatalyst.com/data-mining-inhealthcare

[8] https://books.google.co.in/books?hl=en\&lr=\&id=sp3MB QAAQBAJ\&oi=fnd\&pg=PA211\&dq=data + mining + in $+\mathrm{h}$ ealthcare\&ots=nw5xjyh_GW\&sig=DvAUOYdcx0UyI8e $\mathrm{tUwJ} 0 \mathrm{Rzo} 8 \mathrm{~S} 1 \mathrm{Q} \# \mathrm{v}=$ onepage \&q\&f$=$

[9] https://knifedge.wordpress.com/2012/07/05/increasingsales-for-local-medicine-shops/

[10] http://www.asapnet.org/files/January2014/Presentations/ ASAPJan14_Presentations10_Dietz1.pdf

[11] http://bear.warrington.ufl.edu/weitz/papers/Increasing_S ales.pdf

[12] https://www.google.co.in/webhp?sourceid=chromeinstant\&ion=1\&espv=2\&ie=UTF-8\#q=bar\%20 chart

[13] https://en.wikipedia.org/wiki/RapidMiner 